\title{
Protection of copper from corrosion with nicotinamide inhibitor
}

\section{ABSTRACT}

C opper is used extensively in industry since its superior metallic properties. Since the corrosion resistance of copper is low in acidic media, it is important to apply corrosion prevent methods. In this study, the environmentally friendly nicotinamide compound was used as an inhibitor to protect copper from corrosion. In this study, firstly, the Cyclic Voltammetry Technique was used to determine the electrochemical behavior of copper in $0.1 \mathrm{M} \mathrm{HCl}$ acid solution. Then, Tafel polarization method was applied to determine the corrosion behavior of copper in $0.1 \mathrm{M} \mathrm{HCl}$ acid solution in the absence of nicotinamide inhibitor and in the presence of $500 \mathrm{ppm}, 750 \mathrm{ppm}, 1000 \mathrm{ppm}$ nicotinamide. The optimum time was determined for each concentration by keeping the inhibitor at these 3 different concentrations for $0,15,30,45$ and 60 minutes. The highest inhibition efficiency was obtained as $95.3 \%$ in $1000 \mathrm{ppm}$ nicotinamide concentration in 30 minutes residence time, and the best corrosion potential was $-0.145 \mathrm{~V}$ in $1000 \mathrm{ppm}$ nicotinamide concentration in 45 minutes residence time. $750 \mathrm{ppm}$ inhibitor concentration can be used in cases where the duration is not important, as the inhibition efficiency value is reached as $94.6 \%$ in a 60 minutes residence time at a $750 \mathrm{ppm}$ nicotinamide concentration.

\section{Keywords:}

Copper; Corrosion; Tafel Polarization; Nicotinamide; Inhibitor

\section{Article History: \\ Received: 2021/08/21 \\ Accepted: 2021/og/27 Online: $2021 / 09 / 29$}

Correspondence to: Gulden Asan, Hitit University, Vocational School of Technical Sciences, Occupational Health and Safety Program, Corum/Turkey E-Mail:guldenasan@hitit.edu.trPhone: +90 (507) 9238341 Fax:

\section{INTRODUCTION}

Copp opper is one of the first minerals to be mined and processed in human history. Although gold first attracted the attention of human beings, copper has been widely used by human beings because it can be found in every part of the world and can be easily processed. B.C. Bronze is a copper-tin alloy that gives its name to the period between 3000-1800 (Bronze Age). Copper has found a wide range of uses because it is the metal that conducts electricity the best after silver and makes alloys of industrial importance. Depending on the economic development, the usage areas of copper are increasing day by day. It is so important to protect such an important metal from corrosion [1]. Corrosion causes billions of dollars in economic loss, terrible safety hazards and environmental pollution each year [2,3]. While copper has high corrosion resistance in neutral and slightly alkaline media, it is not resistant to corrosion in acidic media $[4,5]$. Acid solutions are widely used in industry. These solutions are generally corrosive. Therefore, inhibitors are widely used to reduce the corrosive effect on metallic material [6]. Different methods such as suitable design, use of alloys, changing the media, surface coatings and use of inhibitors are used to protect metals from corrosion [7]. We can classify the applied methods as electrochemical methods, chemical methods and surface coating. Electrochemical methods; can be counted as cathodic protection and anodic protection. The use of inhibitor applied in this study is a corrosion protection method applied in chemical methods [8]. We can divide the inhibitors used in corrosion protection as inorganic inhibitors and organic inhibitors. Inhibitors generally adsorb to the surface to form a protective film on the metal surface, thus providing protection against corrosion $[9,10]$. In organic inhibitors; Heteroatoms such as nitrogen, sulphur and phosphorus increase the corrosion inhibitory effectiveness $[11,12]$. The electron donating atoms of heteroatoms such as nitrogen, sulfur and phosphorus in the organic compound and the d orbitals on the copper atom form coordinated bonds and work as corrosion inhibitors for copper [13,14]. When the use of inhibitors in corrosion protection finds application, the aim is more effective protection, but today, only corrosion protection is not sufficient. Because many of the inhibitors are expensive and threaten the environment and human health with their toxic effects [15]. Today, an environment-friendly inhibitor called 
green inhibitor has been investigated $[16,17]$. The nicotinamide used in this study is vitamin B3. For this reason, nicotinamide inhibitor is an environmentally friendly chemical that is not harmful to human health and even beneficial $[18,19]$. This situation increases the importance of the study. Our previous study also proved that nicotinamide is an effective inhibitor in protecting aluminum from corrosion [20]. In this study, the inhibition efficiency of nicotinamide on copper corrosion in acidic medium was investigated.

\section{MATERIAL AND METHODS}

In the experiments, corrosion resistance of copper in 0.1 $\mathrm{M} \mathrm{HCl}$ acid medium and after the addition of nicotinamide at different concentrations was measured with the Ivium Technologies De Regent 1785611 HW Eindhoven model device using Cyclic Voltammetry Method and Tafel Polarization Method. As it is known, corrosion occurs when two electrochemical reactions between the metal and the solution medium come into equilibrium. One of these reactions is the anodic reaction and is formed by the dissolution of the metal. The other reaction is the cathodic reaction that occurs with the reduction of $\mathrm{O}_{2}$ or $\mathrm{H}^{+}$ in the solution. In the Tafel Polarization Method, anodic and cathodic Tafel curves are obtained for the corroded metal, and the linear parts of them are extended and the corrosion rate $\left(\mathrm{I}_{\text {cor }}\right)$ and corrosion potential $\left(\mathrm{E}_{\text {cor }}\right)$ for that system are found from the cut points. Measurements were carried out in a three-necked corrosion cell. A copper electrode embedded in polyester resin and a surface area of $1 \mathrm{~cm}^{2}$ was used as the working electrode, a Pt plate as the counter electrode, and a saturated calomel electrode placed in the lugin as the reference electrode. Before each measurement, the surface of the working electrode was cleaned with 4000 grit sandpaper. Then it was made ready for use by passing through pure water and ethyl alcohol. The acid solution was prepared using Merck brand 37\% Hydrochloric Acid solution and distilled water. As an inhibitor, Nicotinamide (Sigma Aldrich) was added to the solution at different concentrations and measurements were taken. The molecular structure of nicotinamide is shown in Figure 1.

\section{RESULTS AND DISCUSSION}

To determine the electrochemical behavior of copper in $0.1 \mathrm{M} \mathrm{HCl}$ acid solution, cycling voltammograms were taken between $-1.0 \mathrm{~V}$ and $+0.2 \mathrm{~V}$ at a scanning rate of $200 \mathrm{mV} / \mathrm{s}$. With cyclic voltammetry, information about reduction/oxidation events on the electrode surface, whether it is reversible, diffusion or adsorption can be obtained [21,22]. Figure 2 shows the CV of copper in 0.1 $\mathrm{M}$ hydrochloric acid solution. In the forward potential

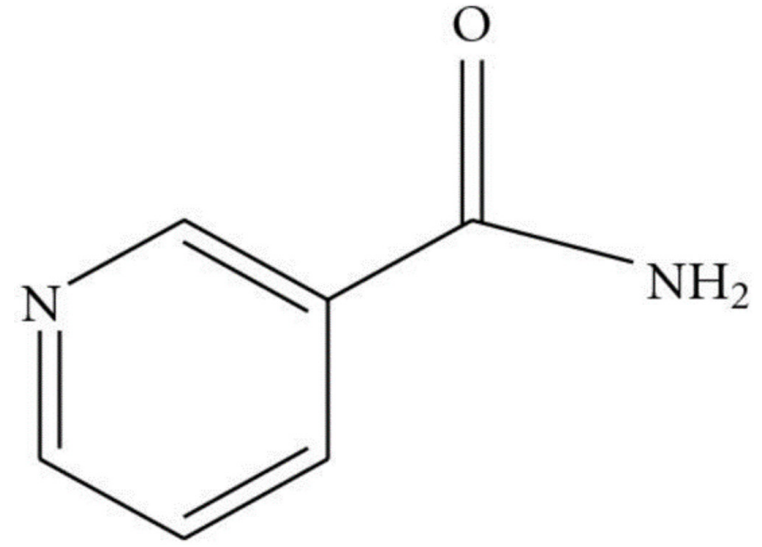

Figure 1. Molecular structure of Nicotinamide.

scanning, anodic current started to pass after $-0.5 \mathrm{~V}$ and there was no increase in this current until $-0.1 \mathrm{~V}$. That is, the metal is in a passive state. However, after this potential, copper is oxidized by giving electrons. By reverse polarization the reduction peak of the oxidized copper is seen after $-0.12 \mathrm{~V}$.

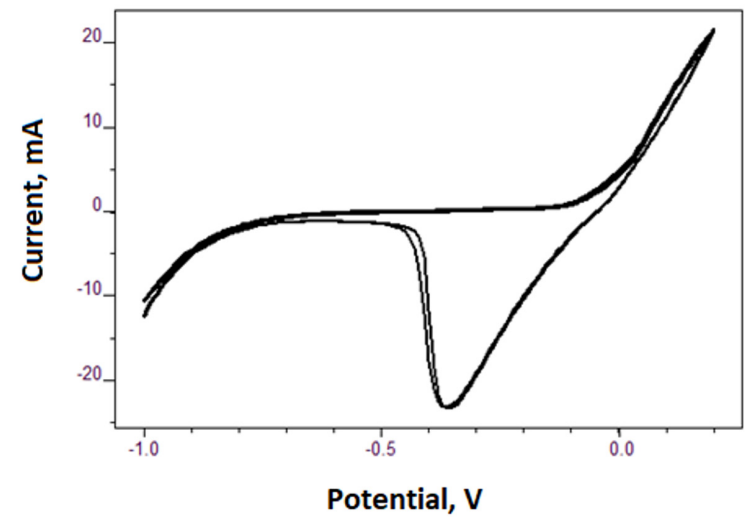

Figure 2. Electrochemical behavior of copper in $0.1 \mathrm{M}$ Hydrochloric acid solution

The addition of an organic corrosion inhibitor provides a protective layer that prevents corrosion on the copper surface by adsorption of inhibitor molecules in a corrosive media [23]. Nicotinamide, used as an inhibitor, was first added to the solution at $500 \mathrm{ppm}$, and the Tafel polarization curve was taken without waiting, and this was called 0 minute measurement. Then, Tafel polarization curves of the copper electrode were taken after waiting for 15, 30, 45 and 60 minutes in order to see the effect of the holding time on the inhibition efficiency. A decrease in the corrosion rate is expected with increasing the holding time of the electrode in the solution containing the inhibitor [24]. It is expected that the corrosion rate will decrease, that is, an increase in the inhibitor's effectiveness, since the inhibitor has been given the opportunity to adhere to the surface by increasing the holding time. These measured values are given in Table 1 .

Tafel polarization curves taken at different residence 
Table 1. Effect of Residence Time on Copper Corrosion in $0.1 \mathrm{M} \mathrm{HCl}$ Solution Containing 500 ppm Nicotinamide

\begin{tabular}{|c|c|c|c|c|c|}
\hline $\begin{array}{l}\text { Concent- } \\
\text { ration, } \\
\text { ppm }\end{array}$ & $\begin{array}{l}\text { Residence } \\
\text { time, } \\
\text { minutes }\end{array}$ & $\begin{array}{c}\mathrm{E}_{\text {cor' }} \\
\mathrm{V}\end{array}$ & $\begin{array}{c}I_{\text {cor }} \\
(\mu \mathrm{A})\end{array}$ & $\begin{array}{l}\text { Corrosion } \\
\text { Rate, } \\
\mathrm{mm} / \mathrm{y}\end{array}$ & $\begin{array}{l}\text { Inhibition } \\
\text { Efficiency } \\
\%\end{array}$ \\
\hline \multirow[t]{3}{*}{0} & 0 & -0.403 & 12.74 & 0.148 & -.. \\
\hline & 0 & -0.351 & 2.72 & 0.032 & 78.7 \\
\hline & 15 & -0.327 & 1.69 & 0.020 & 86.8 \\
\hline \multirow[t]{3}{*}{500} & 30 & -0.258 & 1.59 & 0.018 & 87.5 \\
\hline & 45 & -0.181 & 1.28 & 0.015 & 90.0 \\
\hline & 60 & -0.189 & 1.02 & 0.012 & 92.0 \\
\hline
\end{tabular}

times were superimposed and given in Figure 3. As can be seen from the Figure 3 and the Table 1, the corrosion potential shifted to positive values when the residence time of the copper electrode increased in the media included nicotinamide. This is desirable situation and this demonstrates that copper resists corrosion up to a higher potential [25]. Table 1 shows that although the best corrosion potential seems to have been obtained in 45 minutes of residence time, almost the same potential curves were observed in 60 minutes and in 45 minutes of residence time. The minimum corrosion rate and the inhibition efficiency was determined respectively $0.01183 \mathrm{~mm} /$ year and $92.0 \%$ in the 60 minutes residence time.



Figure 3. Tafel Polarization curves obtained for Copper at different residence times in $0.1 \mathrm{M} \mathrm{HCl}$ solution containing $500 \mathrm{ppm}$ nicotinamide

In order to investigate the effect of nicotinamide concentration on copper corrosion, after 500 ppm nicotinamide was added, $750 \mathrm{ppm}$ and $1000 \mathrm{ppm}$ nicotinamide were added to $0.1 \mathrm{M} \mathrm{HCl}$ solution. Then, the determination of the optimum residence time was made at all concentrations. It is seen at Table 2 and Figure 4, the best corrosion potential and the lowest corrosion rate were obtained in 60 minutes holding. An increase in inhibition efficiency was observed compared to $500 \mathrm{ppm}$ nicotinamide.

Since the inhibition efficiency increased with the increase in the nicotinamide concentration from $500 \mathrm{ppm}$ to 750 ppm, the optimum time was determined by adding 1000
Table 2. Effect of Residence Time on Copper Corrosion in $0.1 \mathrm{M} \mathrm{HCl}$ Solution Containing 750 ppm Nicotinamide

\begin{tabular}{lccccc}
\hline $\begin{array}{l}\text { Concent- } \\
\text { ration, } \\
\text { ppm }\end{array}$ & $\begin{array}{l}\text { Residence } \\
\text { time, } \\
\text { minutes }\end{array}$ & $\begin{array}{c}\mathbf{E}_{\text {cor }}, \\
\mathbf{V}\end{array}$ & $\begin{array}{c}\left.\mathbf{I}_{\text {cor }}, \boldsymbol{\mu A}\right) \\
(\boldsymbol{\mu})\end{array}$ & $\begin{array}{l}\text { Corrosion } \\
\text { Rate, } \\
\mathbf{m m} / \mathbf{y}\end{array}$ & $\begin{array}{l}\text { Inhibition } \\
\text { Efficiency } \\
\%\end{array}$ \\
\hline 0 & 0 & -0.403 & 12.74 & 0.148 & $\ldots$ \\
& 0 & -0.332 & 1.77 & 0.021 & 86.1 \\
750 & 15 & -0.286 & 1.22 & 0.014 & 90.4 \\
& 30 & -0.221 & 0.96 & 0.011 & 92.6 \\
& 45 & -0.206 & 0.88 & 0.010 & 93.1 \\
& 60 & -0.180 & 0.69 & $\mathbf{0 . 0 0 8}$ & $\mathbf{9 4 . 6}$ \\
\hline
\end{tabular}

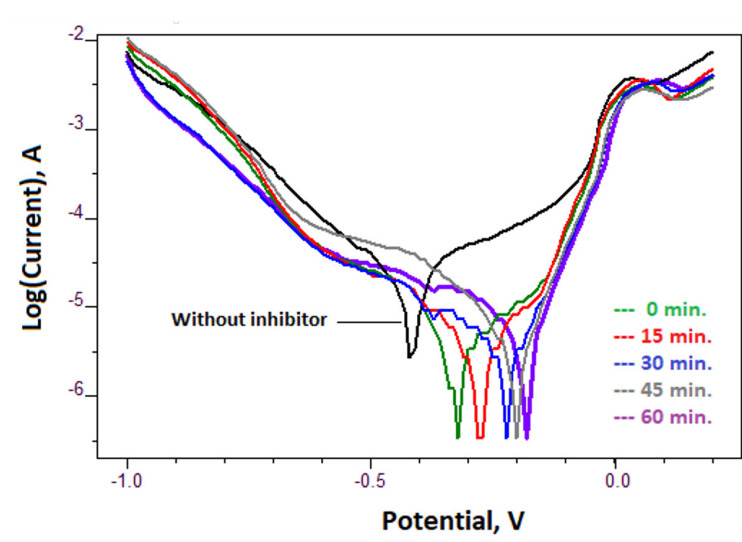

Figure 4. Tafel Polarization curves obtained for Copper at different residence times in $0.1 \mathrm{M} \mathrm{HCl}$ solution containing $750 \mathrm{ppm}$ nicotinamide

ppm nicotinamide to the $0.1 \mathrm{M} \mathrm{HCl}$ solution. Table 3 and Figure 5 show that the best corrosion potential and the lowest corrosion rate were obtained in 30 minutes of waiting. The lowest corrosion rate was $0.007 \mathrm{~mm} /$ year and the inhibition efficiency was $95.3 \%$ in the 30 minutes residence time. A temporal advantage was achieved as the lowest corrosion rate was reached in 30 minutes.

Table 3. Effect of Residence Time on Copper Corrosion in $0.1 \mathrm{M} \mathrm{HCl}$ Solution Containing 1000 ppm Nicotinamide

\begin{tabular}{lccccc}
\hline $\begin{array}{l}\text { Concent- } \\
\text { ration, } \\
\mathbf{p p m}\end{array}$ & $\begin{array}{l}\text { Residence } \\
\text { time, } \\
\text { minutes }\end{array}$ & $\begin{array}{c}\mathbf{E}_{\text {cor }}, \\
\mathbf{V}\end{array}$ & $\begin{array}{c}\left.\mathbf{I}_{\text {cor }}, \boldsymbol{\mu}\right) \\
(\boldsymbol{\mu})\end{array}$ & $\begin{array}{l}\text { Corrosion } \\
\text { Rate, } \\
\mathbf{m m} / \mathbf{y}\end{array}$ & $\begin{array}{l}\text { Inhibition } \\
\text { Efficiency } \\
\mathbf{\%}\end{array}$ \\
\hline 0 & 0 & -0.403 & 12.74 & 0.148 & $-\ldots$ \\
& 0 & -0.237 & 1.33 & 0.015 & 89.9 \\
& 15 & -0.188 & 1.05 & 0.012 & 91.9 \\
1000 & 30 & -0.168 & 0.58 & $\mathbf{0 . 0 0 7}$ & $\mathbf{9 5 . 3}$ \\
& 45 & -0.145 & 0.93 & 0.011 & 92.6 \\
& 60 & -0.157 & 1.57 & 0.018 & 87.8 \\
\hline
\end{tabular}

\section{CONCLUSION}

As a result, nicotinamide proved to be an effective inhibitor in protecting copper from corrosion. Figure 6 shows that the corrosion potential after 60 minutes of waiting at $500 \mathrm{ppm}$ nicotinamide concentration is $-0.189 \mathrm{~V}$, and 


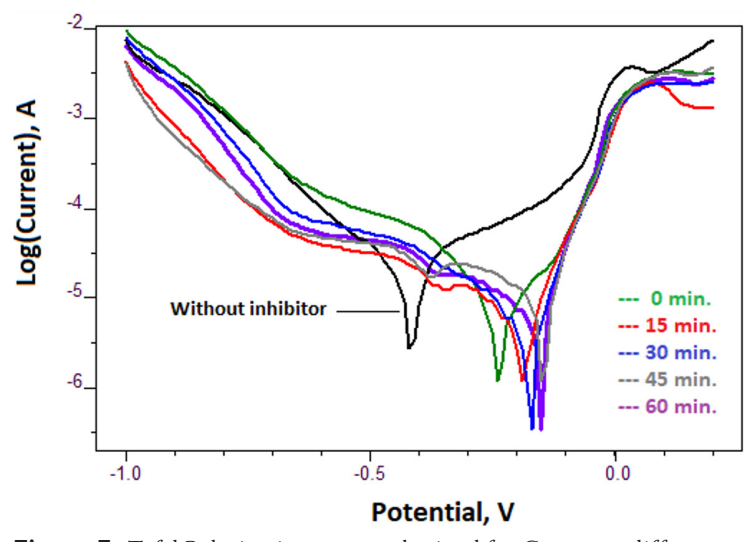

Figure 5. Tafel Polarization curves obtained for Copper at different residence times in $0.1 \mathrm{M} \mathrm{HCl}$ solution containing $1000 \mathrm{ppm}$ nicotinamide

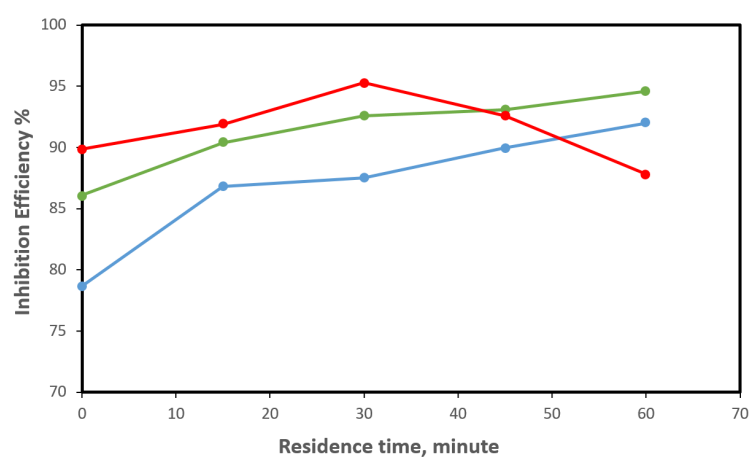

$\rightarrow 500 \mathrm{ppm} \rightarrow 750 \mathrm{ppm} \rightarrow 1000 \mathrm{ppm}$

Figure 6. Tafel Polarization curves obtained for Copper at different residence times in $0.1 \mathrm{M} \mathrm{HCl}$ solution containing different concentration (500 ppm, $750 \mathrm{ppm}$ and $1000 \mathrm{ppm}$ ) nicotinamide

the inhibition efficiency is $92.0 \%$. After 60 minutes of soaking at $750 \mathrm{ppm}$ nicotinamide concentration, the corrosion potential increased to $-0.180 \mathrm{~V}$ and the inhibition efficiency increased to $94.6 \%$. This showed us that the adsorption to the surface is not sufficient at $500 \mathrm{ppm}$ concentration, but when the concentration is increased to $750 \mathrm{ppm}$, the inhibition efficiency increases with the increase in surface adhesion. When the concentration increased to $1000 \mathrm{ppm}$, the lowest corrosion rate was reached in 30 minutes and thus the residence time was halved. Inhibition efficiency of $95.3 \%$ was obtained at 1000 ppm nicotinamide concentration in 30 minutes residence time. At 1000 ppm nicotinamide concentration, a decrease in inhibition efficiency was observed when the 30 minutes residence time was exceeded. When the concentration was increased more than the molecules to be adsorbed, that is, if there were more inhibitor molecules in the media, the corrosion rate was negatively affected. It can be thought that when the protective layer becomes thicker in adsorption, permeability may increase by forming defects on the surface, which leads to a decrease in corrosion resistance. The corrosion potential shifted to more positive values at all three concentrations, thus providing an advantage in corrosion protection. It is advantageous to use $750 \mathrm{ppm}$ nicotinamide concentration when there is no time restriction, and to use $1000 \mathrm{ppm}$ nicotinamide concentration when it is desired to provide faster protection. Nicotinamide has proven that it can be used safely in the protection of copper from corrosion due to its environmental friendliness and high corrosion inhibitory effectiveness.

\section{CONFLICT OF INTEREST}

Author approve that to the best of their knowledge, there is not any conflict of interest or common interest with an institution/organization or a person that may affect the the review process of the paper.

\section{References}

1. A. Fateh, M. Aliofkhazraei, A.R. Rezvanian, Review of corrosive environments for copper and its corrosion inhibitors, Arabian Journal of Chemistry. 13 (2020) 481-544. https://doi.org/10.1016/j. arabjc.2017.05.021.

2. R. Javaherdashti, How corrosion affects industry and life, AntiCorrosion Methods and Materials. 47 (2000) 30-34. https://doi. org/10.1108/00035590010310003.

3. X.F. Zhang, Y.Q. Chen, J.M. Hu, Robust superhydrophobic SiO2/ polydimethylsiloxane films coated on mild steel for corrosion protection, Corrosion Science. 166 (2020). https://doi.org/10.1016/j. corsci.2020.108452.

4. G. Tansuğ, T. Tüken, E.S. Giray, G. Findikkiran, G. Siğircik, O. Demirkol, M. Erbil, A new corrosion inhibitor for copper protection, Corrosion Science. 84 (2014) 21-29. https://doi.org/10.1016/j. corsci.2014.03.004.

5. G. Moretti, F. Guidi, Tryptophan as copper corrosion inhibitor in $0.5 \mathrm{M}$ aerated sulfuric acid, Corrosion Science. 44 (2002) 1995-2011. https://doi.org/10.1016/S0010-938X(02)00020-3.

6. Q.B. Zhang, Y.X. Hua, Corrosion inhibition of mild steel by alkylimidazolium ionic liquids in hydrochloric acid, Electrochimica Acta. 54 (2009) 1881-1887. https://doi.org/10.1016/j. electacta.2008.10.025.

7. R. Natarajan, F.S. Zahir Said Al Shibli, Synthesis of biomass derived product from Ziziphus spina-christi and application for surface protection of metal under acidic environment- Performance evaluation and thermodynamic studies, Chemosphere. 284 (2021) 131375. https://doi.org/10.1016/j.chemosphere.2021.131375.

8. J.M. Gaidis, Chemistry of corrosion inhibitors, Cement and Concrete Composites. 26 (2004) 181-189. https://doi.org/10.1016/ S0958-9465(03)00037-4.

9. C.N. Hippolyte, B.Y. Serge, A. Sagne, J. Creus, T. Albert, Nicotinamide Inhibition Properties for Copper Corrosion in 3.5\% $\mathrm{NaCl}$ Solution: Experimental and Theorical Investigations, Journal of Materials Science and Chemical Engineering. 06 (2018) 100-121. https://doi.org/10.4236/msce.2018.63008.

10. H. Gerengi, H.I. Ugras, M.M. Solomon, S.A. Umoren, M. Kurtay, N. Atar, Synergistic corrosion inhibition effect of 1-ethyl-1methylpyrrolidinium tetrafluoroborate and iodide ions for low carbon steel in $\mathrm{HCl}$ solution, Journal of Adhesion Science and Technology. 30 (2016) 2383-2403. https://doi.org/10.1080/0169424 3.2016.1183407.

11. A. Asan, M. Kabasakaloğlu, M. Ișiklan, Z. Kiliç, Corrosion inhibition of brass in presence of terdentate ligands in chloride solution, Corrosion Science. 47 (2005). https://doi.org/10.1016/j. 
corsci.2004.07.031.

12. R. Natarajan, F. Al Shibli, Corrosion inhibition of aluminum under basic conditions using Medicago sativa L. extract thermodynamic studies, Korean Journal of Chemical Engineering. 38 (2021) 1-10. https://doi.org/10.1007/s11814-021-0851-z.

13. M.M. Antonijevic, M.B. Petrovic Mihajlovic, Copper Corrosion Inhibitors. Period 2008-2014. A Review, International Journal of Electrochemical Science. 10 (2015) 1027-1053. http://electrochemsci. org/papers/vol10/100201027.pdf.

14. B. Tan, S. Zhang, Y. Qiang, W. Li, H. Li, L. Feng, L. Guo, C. Xu, S. Chen, G. Zhang, Experimental and theoretical studies on the inhibition properties of three diphenyl disulfide derivatives on copper corrosion in acid medium, Journal of Molecular Liquids. 298 (2020) 111975. https://doi.org/10.1016/j.molliq.2019.111975.

15. M. Bethencourt, F.J. Botana, J.J. Calvino, M. Marcos, M.A. Rodríguez-Chacón, Lanthanide compounds as environmentallyfriendly corrosion inhibitors of aluminium alloys: A review, Corrosion Science. 40 (1998) 1803-1819. https://doi.org/10.1016/ S0010-938X(98)00077-8.

16. P.B. Raja, M.G. Sethuraman, Natural products as corrosion inhibitor for metals in corrosive media - A review, Materials Letters. 62 (2008) 113-116. https://doi.org/10.1016/j.matlet.2007.04.079.

17. P. Mourya, S. Banerjee, M.M. Singh, Corrosion inhibition of mild steel in acidic solution by Tagetes erecta (Marigold flower) extract as a green inhibitor, Corrosion Science. 85 (2014) 352-363. https:// doi.org/10.1016/j.corsci.2014.04.036.

18. S. Bashir, V. Sharma, S. Kumar, Z. Ghelichkhah, I.B. Obot, A. Kumar, Inhibition performances of nicotinamide against aluminum corrosion in an acidic medium, Portugaliae Electrochimica Acta. 38 (2020) 107-123. https://doi.org/10.4152/pea.202002107.
19. X. Liu, X. Pan, M. Lu, Y. Sun, Z. Wang, Y. Zheng, Nicotinic acid derivatives as corrosion inhibitors for mild steel in hydrochloric acid solutions: an experimental and computational chemistry study, Journal of Adhesion Science and Technology. 35 (2021) 63-80. https://doi.org/10.1080/01694243.2020.1787934.

20. G. Asan, A. Asan, H. Çelikkan, The effect of 2D-MoS2 doped polypyrrole coatings on brass corrosion, Journal of Molecular Structure. 1203 (2020). https://doi.org/10.1016/j. molstruc.2019.127318.

21. M. Okutan, Electrochemical determination of ascorbic acid with thermally reduced graphene oxide, Journal of the Faculty of Engineering and Architecture of Gazi University. 35 (2020) 15891601. https://doi.org/10.17341/gazimmfd.645284.

22. T.T. Calam, Investigation of the electrochemical behavior of phenol using 1H-1, 2, 4-triazole-3-thiol modified gold electrode and its voltammetric determination, Journal of the Faculty of Engineering and Architecture of Gazi University. 35 (2020) 835-844. https://doi. org/10.17341/gazimmfd.543608.

23. R. Ravichandran, N. Rajendran, Electrochemical behaviour of brass in artificial seawater: Effect of organic inhibitors, Applied Surface Science. 241 (2005) 449-458. https://doi.org/10.1016/j. apsusc.2004.07.046.

24. G. Moretti, F. Guidi, G. Grion, Tryptamine as a green iron corrosion inhibitor in $0.5 \mathrm{M}$ deaerated sulphuric acid, Corrosion Science. 46 (2004) 387-403. https://doi.org/10.1016/S0010-938X(03)00150-1.

25. T. Ohtsuka, Corrosion protection of steels by conducting polymer coating, International Journal of Corrosion. 2012 (2012). https://doi. org/10.1155/2012/915090. 